\title{
The Rate of Local Integration in the Supply Chain of A Car Manufacturer
}

\author{
Raissouni Rajaa, Hamiche Mhamed \\ Laboratoire de Gestion, Economie et développement durable \\ Université Abdelmalek Essaadi \\ Tanger, Morocco \\ rajaaraissouni@gmail.com, Hamiche2020@gmail.com
}

\begin{abstract}
The rate of local integration is the share of production produced in Morocco in a context of production broken out around the world by multinationals When all the parts of an automobile are imported into Morocco and then assembled on the spot before being re-exported in the form of whole cars by a builder, then local integration comes down to assembly

Local integration is a permanent challenge for Morocco's industrial policy. It is about bringing into the realm not a builder or two, but all their chain of subcontracting. "The challenge is to become the backbone of Europe for sourcing", and according to Renault Maroc, this sourcing "integrates local purchases and also export (excluding vehicles)". It is understood that the project aims to position Morocco as an exporter of automotive components of first rank. Moreover, the group is a VRP in Morocco since it has hosted 250 international suppliers in the Tangiers plant "to present the new ecosystem, the industrial platform of Tangiers, to encourage them to invest in our country." It is also learned that the local integration platform that will be created will include purchasing, engineering and logistics resources in order to optimize local sourcing and to make Morocco a solid industrial export base.

In this article, we question the impact of local integration on the supply chain of Renault Morocco, which leads us to ask the following question : Does the increase in the local integration rate reduce the purchase costs of the multinational Renault?

In this regard, we adopted a two-step approach: First we focused on the conceptual aspects of the purchasing function and the theoretical basis of sourcing. Secondly then presented a project for local integration and diagnosis of the body \& Electrical perimeter applied within the company Renault Morocco.

Keywords-Supply chain; Local integration rate ; Automobile industry; Sourcing procedures; sourcing practice.

Important note :The amounts and prices reported in the article are approximate figures and are not actual prices.
\end{abstract}




\section{Introduction}

The automobile industry has become Morocco's leading export market and one of the most successful industrial pillars in the Moroccan industry. First with the establishment of Renault Tanger in 2008, which is the biggest foreign investment in Moroccan history, furthermore with the anticipated arrival of Peugeot-Citroën (PSA) in Kenitra in 2019; therefore, Morocco remains an attractive country for major car makers due to its political stability and favorable geographical position compared to its neighbors in the region.

The development of a solid industrial fabric is the result of further integration of the automotive value chain in Morocco. Indeed, the year 2016 testifies to the signing of supplier agreements called Ecosystem, mobilizing investments of the order of 10 billion dirhams.

These agreements were signed in the presence of His Majesty King Mohamed IV and several ministers as well as the Director of Operations, of the Renault group Middle East and India branch. This project involves developing a global supply platform that generates a figure of 20 billion dirham per year. It will contribute to the creation of 50,000 new permanent jobs with the objective of doubling this number by 2020 to more than 160000. In short, the ecosystem signed in April 2016 includes three types of agreements:

$>$ A framework agreement on the establishment of the Renault ecosystem.

$>$ An industrial property agreement.

$>$ A convention on executive training and vocational training in the automotive sector.

Morocco commits to give subsidies to investments and tax advantages to suppliers who intend to settle within the country. Renault took advantage of this ecosystem agreement by increasing its local integration rate and consequently reducing and optimizing its logistics and purchasing costs.

Generally, the purchasing costs of multinationals such as Renault represent a significant percentage of the cost of their products. To this end, they still hope to optimize them by several levers, local sourcing is a strategic tool to achieve this objective through its direct contribution to the purchasing performance and consequently the company's performance.

\section{Literature review: Conceptual aspects of the purchasing function and the theoretical basis of sourcing}

\subsection{Conceptual Aspects of Purchasing}

\subsubsection{Definition of purchases}

The concept of purchase has no universally known definition. This is the reason why there are several variants of the purchase functions in companies. Besides, it would be easy to generalize this definition by defining the purchasing function as "Function responsible for the acquisition of the goods or services necessary for the proper functioning of the enterprise". More precisely, the purchase's mission is to acquire the goods and services required, at the desired quality level, in the desired quantities, within the expected timeframes and in the best conditions of service and security of supply.

The purchasing function contributes directly to the company's corporate strategy. Today, it is difficult to increase profit by sales, but it is possible to improve a company's productivity by reducing costs and improving the technical definition of the product. 
Organizations have long neglected the purchasing function. Yet purchases account for an average of $70 \%$ of the turnover of industrial companies. Globalization has reinforced the impact of the purchasing function on the company's performance in terms of quality, cost and time.

Indeed, the purchase function is the intermediary between the internal services and the suppliers. In order to meet the specific expectations of each department of the company (production, logistics, development, etc.), the buyer is obliged to know the characteristics of suppliers and their products and services requested. In order to be as efficient as possible, it is important to keep a watch on the market to know its trends and the various suppliers present and likely to satisfy the need of the company.

In addition, the purchasing function differs categorically from that of supply. This problem of confusion and mixing has always been questioned by researchers. For this, and before projecting into the fundamental aspects of the purchase, an explanation of the difference between the supply and the purchase is necessary.

\subsubsection{The economic and strategic stakes of the purchasing function:}

\section{Economic issues}

The preponderant role played by business purchases is due in large part to a favorable economic and social environment. The main justifications that could be mentioned are:

$>$ A growing global economy.

$>$ An improvement in the living conditions of individuals.

$>$ The development and the explosion of new information and communication technologies (ICTs).

$>$ The transition from a production economy to a market economy.

\section{Sustained economic growth}

Business activities were revived with the return to growth. This growth is reflected in several ways. First, an increase in demand, in terms of quantity but above all in terms of quality, has forced companies to increase their productivity. This situation leads companies to constantly seek the best economic, technical and industrial policies to be able to satisfy this demand.

Secondly, we have the phenomena of globalization and internationalization that bring companies, notably through mergers and acquisitions, to integrate new markets and thus find new outlets for their products. However, it should be stressed that this economic growth also leads to increased competition. This is becoming so harsh that only companies that are innovative, adaptable and competitive can survive to meet the demands and quality needs of ever-increasing and increasingly demanding consumers.

\section{The development of NICTs}

With NICTs, especially the Internet and Intranet, there is an increasingly strong structuring in the management and dissemination of information internally. Thanks to these technologies, companies have new tools allowing them to constantly update the data but also to disseminate it to all the employees concerned, which allows a collaboration almost in real time.

\section{Transition to a market economy}

To these first observations, we can add the fact that over the past two decades we have gradually shifted from a production economy to a market economy. But we will return to this change in more detail because 
Raissouni Rajaa, Hamiche Mhamed, The Rate of Local Integration in the Supply Chain of A Car Manufacturer. Transactions on Machine Learning and Artificial Intelligence, Vol 5 No 4 August (2017); p: 803-825

it is one of the factors explaining the evolution of the purchasing function. Faced with all these factors, companies have had to create new capabilities that allow them to generate productivity gains and significantly reduce their costs to compete while satisfying their customers. It was on this principle that the procurement function was created.

\section{Strategic issues}

\section{The Search for Better Competitiveness}

International competition is forcing all companies to increase their competitiveness. To do so, during the 1970s, the traditional strategic lever was to develop commercial investments, in conjunction with the various productivity actions implemented in factories. These measures have often been effective, but the gradual stabilization of results has led the Directorates-General to move towards an area that is still underexploited: Purchasing. The main reasons are:

$>$ The share that the purchase items represent in the income statement. If we consider that beyond the raw materials and components, the various forms of subcontracting, industrial services of all types are purchases.

$>$ For the last 10 years, large firms have often chosen to focus on one (or some) core business and thus abandon industrial activities

$>$ Previously integrated into certain sectors, in addition, the purchase of complete functions is gradually replacing outsourcing: an increasing share of value added is transferred to suppliers

$>$ Finally, purchases constitute an area in which gains (savings) are made in exchange for low investments (mainly men and information system): the leverage effect is interesting and savings are quickly Income statement.

\section{Developing the Mastery of Technologies}

The second key factor of competitive advantage is the development and management of a technological heritage. Almost always, the company does not have sufficient human and material resources to master all the technologies necessary for the development of its products. Moreover, in the high-tech sectors, the high cost of study and development equipment, as well as that of industrial processes, make it impossible to depreciate them on even average quantities and impose specialization in industrial sectors. Thus, the field of procurement of industrial policy to be carried out in relation to suppliers becomes a new strategic factor.

\section{Mastering High Quality and Providing High Level Service}

Quality assurance and quality control procedures for purchases impose a particular requirement in that they involve the implementation of various external audits and the steering of suppliers in the framework of permanent progress plans.

As for the notion of service, it is expressed mainly by the implementation of a reduction of the time, in order to minimize the dysfunctions and to gain in reactivity. Once this objective has been achieved internally in the plant, as well as in the downstream distribution system, the interfaces with the suppliers have to be developed, and this belongs to the purchasing domain. 


\section{Minimize Development Cycles}

Nowadays, winning companies are the ones that manage to reduce all cycles, from initial product design to delivery to customers (time-to-market concept).

Thus, to reduce industrial delays, there are also actions to optimize the design and development processes of new products. Those who do so can afford to renew their product range faster than competitors, and can thus shorten their lifetimes.

\subsubsection{The purchase cost}

The purchase cost is made up of everything that the element cost, excluding recoverable taxes, from its conception until its entry in the store or its put in use. It is therefore composed of:

$>$ The amount shown on the purchase invoices net of trade reductions and recoverable taxes;

$>$ Of all costs related to the purchase (ancillary costs to purchase) such as third party transport, customs duties, commissions and brokerage and installation costs ...;

$>$ Possibly, procurement costs, some components of which have problems in their allocation (acquisition, receipt, handling, accounting, etc.).

The determination of purchase costs is essential for the good, nature of goods or materials or supplies. It is for the purpose of enabling the recording in the accounts of fixed assets or stocks in accordance with the directives of the accounting law of 1983.

\subsection{Sourcing strategies}

Sourcing is the research, location, selection and evaluation of a supplier in order to meet an identified need. However, in a context of globalization, multinationals manage sourcing around the world by managing a global supply chain for their production sites scattered across the globe. To do this, multinationals seek to reduce the logistical costs of their factories by looking for locally installed suppliers who can supply and deliver according to their specific standards.

\subsubsection{Sourcing strategies according to the supplier panel}

\section{The different sourcing strategies}

\section{Sole sourcing}

It is a single source of supply for one type of product. It can be the result of sourcing from a supplier whose production capacities are rare in the market; But it would be wise to look at the supplier market to compare the supply of other suppliers with the one already contracted.

The use of a single supplier presents a strategic risk insofar as an incident can lead to a break in the supply chain, the consequence of which can be damaging for the enterprise. The link between sole sourcing and supplier relations gives rise to a less formal and longer-term contact. But having a sole sourcing strategy to increase quality is not always true.

\section{Dual sourcing:}

It involves using two suppliers to produce the same component or buy the same raw material. In general the business is shared for $70 \%$ with the supplier $Y$ and $30 \%$ with the supplier $X$. It is in some way a response to the risk of the single source of supply since the supplier acts as a backup in case the other would be 
Raissouni Rajaa, Hamiche Mhamed, The Rate of Local Integration in the Supply Chain of A Car Manufacturer.

Transactions on Machine Learning and Artificial Intelligence, Vol 5 No 4 August (2017); p: 803-825

failing. Many companies consider dual sourcing as important because it allows the company to have some flexibility as well as avoid being frozen by long-term contracts with a single supplier.

\section{Multi sourcing:}

Multi sourcing is when three or more suppliers are used by the company for the same product. This corresponds to a strategy of diversifying sources of supply when, for example, a parent company orders from a number of suppliers close to its factories and markets a similar product to supply the local demand.

\section{Back-up strategies}

\section{Cross sourcing:}

Cross sourcing is a sourcing strategy in which a company uses a supplier in the production of a good or service for a production domain of the company and another supplier producing the same good or service for another area of production line.

The idea is to have a back up supplier and develop a competition between the two suppliers for future contracts to be awarded. Competition between suppliers is a means of encouraging emulation but should not be an instrument of pressure of the client company on its supplier.

\section{Suppliers of fluctuating demand}

Some industries experience a peak demand during a season of the year. They use a supplier that produces continuously during the year. During the strong period, one or more other suppliers will support the peak demand. The degree of strategic relationship with the temporary supplier is not necessarily very high.

Sometimes it serves as a "spare wheel", thing that hampers to carry out a strategic purchasing policy with a reduction in prices and the appearance of innovation.

\subsubsection{The geo-location of the company and the location of resources}

\section{Ocal sourcing}

Local sourcing involves working with regional or national suppliers, defined according to the location of a business activity as a factory. Local sourcing has the advantage of reducing the risks associated with logistics. Another advantage is to benefit from a product delivered with speed, when the freshness of the products is critical or when the demand evolves quickly.

For a company that does not internationalize its sourcing, local sourcing provides, at a lower cost, a developed network of partner suppliers to cover the demand in either local or international markets. However, if these sourcing concerns manufactured product in a declining cycle, low-end, designed by unskilled employees, the local sourcing in certain regions is not advantageous because costs become the first criterion.

\section{International sourcing}

International sourcing is possible through the development of transport and telecommunications which makes it more accessible. This international sourcing is used to benefit from a comparative advantage like that of Silicon Valley where innovations are strong because emulation is favored. Thus appears a geography of sourcing where the firms look for quality in some leading countries like France, Japan, Germany and the United Kingdom . 
International sourcing has developed with the emergence of competitive players outside the borders. With the collapse of the Soviet Union, China's openness, WTO agreements, the development of NAFTA, raw materials, plastics, electronics are bought more frequently from international sources.

This sourcing is adapted when, for manufactured products, the time taken for ship delivery is not paramount. Otherwise the airway remains a possibility to transport in the emergency but its use is very expensive. International sourcing requires taking into account the total costs of delivery (transport, customs clearance, banking, insurance, quality inspection); Trade regulations, both restrictions and incentives; Time to Market (flexibility); Value-added services (a service which is offered by a supplier and which makes it possible to dispense with one more intermediary); Internet communication tools. The barriers are understanding of international procurement procedures (import licenses, certificates of origin), extended delays, cultural differences, currency risks. Finally, having international suppliers has the effect of increasing the inventory level resulting from a policy of risk reduction (downtime, terrorism, change, policy) that leads to the accumulation of security stocks.

\subsubsection{The sourcing procedure}

\section{Expenditure Analysis, Spend analysis}

Strategic sourcing begins with spend analysis up to the procurement automation process. Spend analysis refers to cost management. It is a way of analyzing cost structures that can be carried out by product or by product groups. The products purchased and the procedures leading to these purchases are analyzed in great detail.

\section{The proactive specifications}

Before a sourcing project, the company establishes a general project plan (mapping) in which it formulates its needs, proposes modes of action in the supplier market, makes internal recommendations, identifies the cost sources (cost drivers). It is the stage of constitution of the proactive specifications. This is the preparation stage prior to the decision to attack (as in marketing) the dense supplier market.

Even before the detailed specifications have been drawn up, it must precede a strategic decision by the company's top management. The intention is specified, communicated and comes into application by the constitution of a sourcing team. The latter will attempt to determine the buying segments where the proactive approach to the supplier market can be carried out. Once defined, the team draws up the complete specifications by consulting the other internal clients in order to guarantee the general approval in a strategy of global strategy known to all.

\section{Data collection and processing}

Any sourcing project, whatever its strategic and geographic orientation, requires the company to collect and analyze all kinds of data in order to prepare the sourcing process and anticipate the risks. This may be data from previous sourcing operations: Results, quality of products purchased, and respect of deadlines by the supplier. This may include data on the economic environment such as inflation rates, world commodity prices, exchange rates and the transport network. Also the buyer is required to learn about the legislative environment. The latter can be very changeable and contain legal gaps in some countries; It is necessary for the firm to guard against possible risks due to non-protection by the law, such as intellectual property. 
Raissouni Rajaa, Hamiche Mhamed, The Rate of Local Integration in the Supply Chain of A Car Manufacturer. Transactions on Machine Learning and Artificial Intelligence, Vol 5 No 4 August (2017); p: 803-825

Generally it is necessary to collect the strategic information that will help to establish the sourcing decision, indeed it is necessary to look for 3 important information:

$>$ Geo-location of supplier: this information will allow defining the logistic flows and the daily rates of delivery.

$>$ Quality of supplier and price: An ISO certification of supplier is very important information that proves the quality of the products.

$>$ Production capacity: knowing the supplier's production capacity will make it possible to know its competitiveness and its flexibility towards an unpredictable increase in demand, which generates large investments.

\section{The offers received and selection suppliers}

Supplier selection is a critical phase in the sourcing process, as it has a significant impact on the company's performance.

Indeed, it is necessary to develop a network of reliable and competitive suppliers so that the company can raise and survive in a competitive environment. However, in order for the company to be able to provide a quality product at a reasonable cost, it must virtually monitor the performance of its suppliers.

However, there are two major problems:

$>$ The determination of the number of suppliers and the mode of relationship with them: this choice is largely influenced by the strategic activity area of the company as well as its management mode,

$>$ The selection of the best suppliers: this problem arises after the determination of the number of suppliers selected, however we will explain in detail in the next section the different techniques designed by researchers in the determination of the best suppliers and the fundamental criteria in the decision of making supplier appointment .

\section{Sourcing practice, analysis and development of local integration}

\subsection{Host organization}

Renault Tanger extends over 300 hectares as an assembly plant with a production capacity of 400,000 vehicles per year. $90 \%$ of the vehicles produced will be destined for export. This site complements Renault's industrial system for low-cost vehicles derived from the Logan platform. It is operational since the beginning of 2012. This plant with a capacity of 400,000 vehicles per year starts with the production of two new entry models: the Lodgy family and a small commercial vehicle named dokker, also declined in a particular vehicle version. This site will increase the volumes and expand the range of the M0 range.

Thus, the Renault Group will be able to meet the sustained demand from customers for entry-level vehicles, renowned for their unparalleled performance / price ratio.

In addition, the site is based on the strategic position of the port of Tangier between the Atlantic and the Mediterranean, a developed and competitive fabric of suppliers, and a workforce trained in the best automotive techniques.

The Renault Nissan factory in Tangier was inaugurated on February 9, 2012 by his majesty King Mohamed VI and Carlos GHOSN, President and CEO of the Renault-Nissan Alliance. L'Usine has direct access to the 
port platform of Tangier Med port. It is also the first automotive factory in the world that has zero jet industrial fluids.

Table 1 : Fact sheet of Renault

Fact sheet

\begin{tabular}{|c|c|}
\hline Social reason & Renault Tanger Exploitation SA \\
\hline Legal form & S.A.S \\
\hline Director & Paul carvalho \\
\hline Number of employees 2016 & $\begin{array}{l}332 \text { Frames, } 890 \text { Employees, } 5900 \text { workers, } 1065 \\
\text { interim }\end{array}$ \\
\hline Address & $\begin{array}{c}\text { Renault Tanger exploitation, Free zone of Melloussa, } \\
\text { Tangier }\end{array}$ \\
\hline Manufactured products & $\begin{array}{c}\text { Lodgy J92 } \\
\text { Dokker FK67 } \\
\text { Sandero X52 } \\
\end{array}$ \\
\hline Factory Certification & Factory $100 \%$ zero emission \\
\hline Area & $\begin{array}{c}300 \text { Hectares, including } 220 \text { hectares of covered } \\
\text { building }\end{array}$ \\
\hline Creation date & 16 January 2008 \\
\hline
\end{tabular}

Table 2 : Key figure for Renault

Key figures

\begin{tabular}{|c|c|}
\hline Number of assembly lines & $\begin{array}{c}\text { 2 lines of assembly: Tangier } \\
\mathbf{1} \text { and Tangier 2 }\end{array}$ \\
\hline Area & $\begin{array}{c}300 \text { Hectares, including 220 } \\
\text { hectares of covered building }\end{array}$ \\
\hline Creation date & 16 January 2008 \\
\hline Production & $\begin{array}{c}400,000 \text { vehicle. / Year at } \\
\text { term }\end{array}$ \\
\hline Number of employees & $\begin{array}{c}7000 \text { at the end of January } \\
\text { 2016 }\end{array}$ \\
\hline Factory Certification & Factory 100\% zero emission \\
\hline 1st phase of the project & $\begin{array}{c}30 \text { vehicle / hour, 200,000 } \\
\text { vehicle / year }\end{array}$ \\
\hline 2nd phase of the project & $\begin{array}{c}60 \text { vehicles / hour, 400,000 } \\
\text { vehicles / year }\end{array}$ \\
\hline Legal form and & $\begin{array}{c}\text { S.A. Caisse de dépôt et de } \\
\text { gestion 47.6\%, Renault SAS } \\
52.4 \% \text { du capital de Renault } \\
\text { Tanger Méditerranée }\end{array}$ \\
\hline
\end{tabular}

\subsection{Presentation of the local integration project and diagnosis of the perimeter body \& Electrical}

\subsubsection{Presentation of the local integration project and its role in improving purchasing performance}

General presentation: Local integration of automotive parts 
Raissouni Rajaa, Hamiche Mhamed, The Rate of Local Integration in the Supply Chain of A Car Manufacturer. Transactions on Machine Learning and Artificial Intelligence, Vol 5 No 4 August (2017); p: 803-825

This trend is motivated by the gains to be made in terms of geographic proximity, lower logistics costs and exchange rate risks. To benefit from the cost advantage, Renault Maroc is looking for local partners for business opportunities in order to establish a Win-Win relationship and also minimize logistical costs.

The supplier's competitiveness remains the main concern of Renault Maroc. To this end, it accompanies these suppliers with the ANPQP (Alliance New Product Quality, Procedure) approach, which is founded by Renault-Nissan to make annual agreements and provide specialized teams for suppliers to transfer knowhow, especially in terms of quality management and competitive production.

The ANQP is the common procedure to cover all the quality assurance activities expected for the POE (Outsourced Product of the Renault plants). It was developed to define the common requirements of Renault and Nissan towards their suppliers from the initialization of the project, through the manufacturing agreement, to the end of production series. The challenge is therefore to reach the objectives qualities, cost, delivery time and overall expectations of the customer.

The problem that generally arises for the design of automobile parts in Morocco is the lack of technology and experience. Indeed, the Moroccan industrial fabric does not have the technologies necessary for the manufacture high quality parts or the human skills necessary for the realization of a project of high posture. However, there are multinationals, established in Morocco to fill the gap, and already part of the Renault-Nissan supplier panel.

The criteria requested by Renault-Nissan Purchasing Organization (RNPO) is a joint purchasing organization between Renault and Nissan, which was set up in 2001 and has gradually evolved to cover $100 \%$ of purchases since 2009. Common purchases Mean that Renault and Nissan have mandated RNPO to build a business panel and monitor the performance of suppliers), for the choice of suppliers is grouped in 4 primary parts:

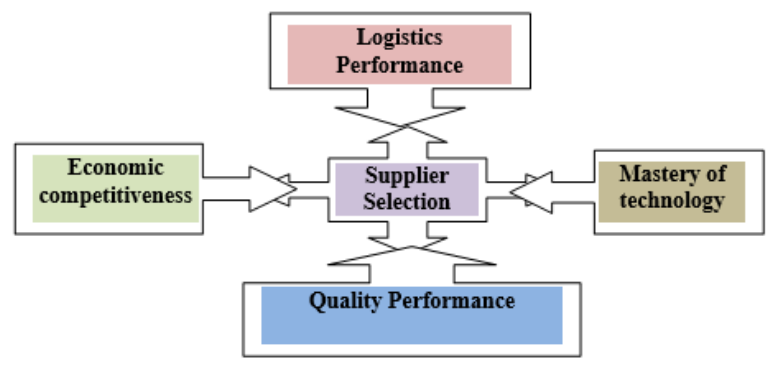

Figure 3: Supplier Choice Criteria at RNPO

Local integration is an effective tool for cost reduction, but the process is slow and requires heavy investment of tools and studies. A profitability study is carried out at the end of the consultations to decide on the profitability of the project for Renault.

Today, the rate of local integration is $33 \%$, which remains very low compared to the targets set at the start of the Renault Tangier plant.

Indeed, the last supplier agreement signed in April 2016, and the establishment of ecosystems, will allow Renault to boost this rate of local integration thanks to permanent support from the Moroccan State, 
specifically the Ministry of Industry for The development of the industrial fabric in Morocco. The objective is to achieve a local integration rate of $65 \%$ by 2023 , which remains a challenge for both stakeholders namely Renault and the Moroccan State. So the local integration project takes into account not only the optimization of costs but also the commitment vis-à-vis the government.

\section{SWOT analysis of local integration}

The SWOT analysis of local integration will enable us to identify, on the one hand, the components on which we can rely and count, and on the other hand, the weaknesses that need to be reinforced. Here is the SWOT analysis:

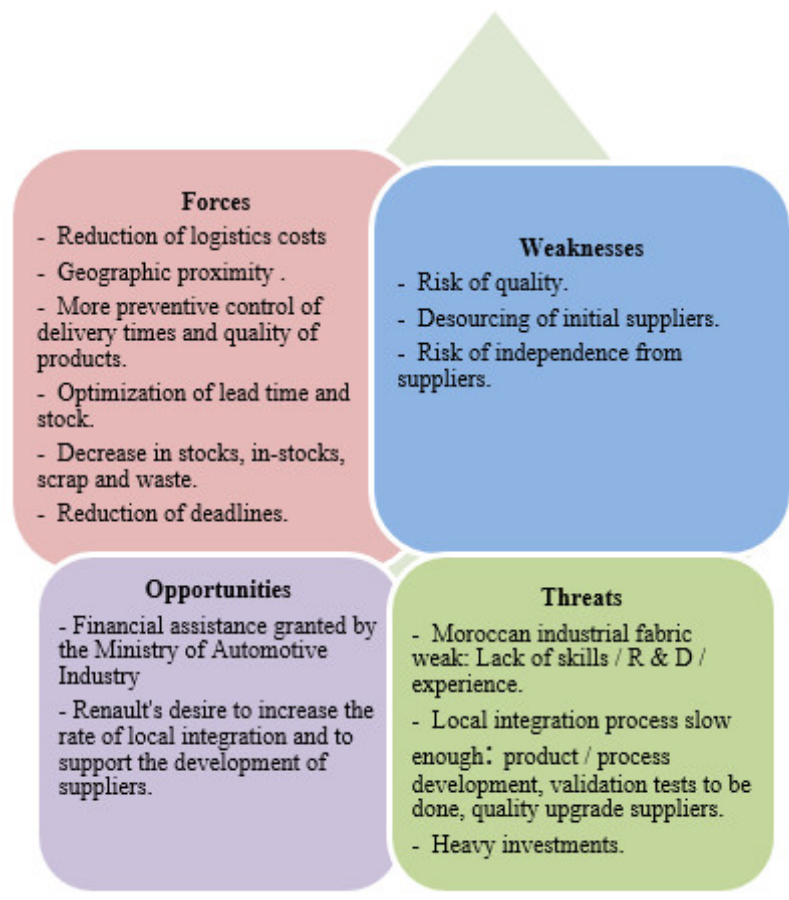

Figure 4: SWOT Analysis of Local Integration

\section{Local integration steps}

The process of local integration takes place in several stages, from the determination of the perimeter impacted up to the appointment of the supplier, which makes sense, since sourcing is a flexible process that changes according to sector of activity and the nature of the business. Below the different actions carried out for each stage of local sourcing:

\section{Step 1: Determine the scope of action:}

In this phase, the following elements are specified:

Identification of the parts concerned.

$>$ Identification of projects.

$>$ Identification of customer sites.

$>$ Determination of current suppliers. 
$>$ Identification of diversity (All existing references), and calculate the mix of references by several criteria either by volume, power train, or product range, the choice of mix depends on the nature of the part.

$>$ Location.

$>$ Prospecting and determination of suppliers to consult (visiting local suppliers, consulting current foreign suppliers for a possible establishment in Morocco).

\section{Step 2: Selection Criteria:}

In this phase, we determine our supplier selection criteria, which are: Geo-location (Integrated multinational suppliers)

$>$ Economic competitiveness.

$>$ Technological mastery.

$>$ Logistics performance.

$>$ Quality performance.

\section{Step 3: Define local integration scenarios:}

After defining the selection criteria, it is recommended to draw a road map for possible scenarios of the local integration.

Step 4: Recovery of engineering definition:

Engineering prepares the technical definition in parallel with the purchase for 3D modeling and 2D of the part.

\section{Step 5: The sending of consultation files to the supplier (Request for information):}

The purchase sends the RFI file. This is the equivalent of the purchase specification.

\section{Step 6: Kick-off meeting with suppliers:}

The purpose of this meeting is to discuss the investments necessary for the start-up of the manufacture of the part.

\section{Step 7: Launching of logistics costing :}

To calculate the necessary transport costs, and compare the new and the old logistic path.

\section{Step 8: Comparative Analysis, Supplier Returns:}

A comparison of the offer of new supplier and the offer of the current supplier, it is done on the following points:

$>$ Price comparison.

$>$ Comparison of logistics costs.

$>$ Comparison TEI (Investment Ticket).

$>$ Comparison of delivery times.

$>$ Comparison of quality.

\section{Step 9: Purchase Negotiation:}

This stage of negotiation is essential for building a lasting relationship with the supplier. 


\section{Step 10: Appointment of Supplier:}

The supplier is appointed for the delivery of the part.

\section{Step 10: Appointment of Supplier:}

The supplier starts the manufacturing process of the part.

Finally, this step is the standard procedure for a local sourcing project, the order of these steps differs from one project to another.

Before starting the project of our integration we will first analyze the inventory of the perimeter purchase Body \& Electrical.

\subsubsection{Analysis of the state of the premises and diagnosis of the perimeter body \& Electrical}

\section{Inventory of fixtures}

The starting point of the project is to do an analysis of the Body \& Electircal perimeter of Renault Maroc. The perimeter that will be analyzed corresponds to everything related to the body of the car and the electronic elements and systems that constitute it.

The Body \& Electircal perimeter is made up of 5 buyers, each one dealing with a number of parts and their suppliers. Some of these parts are locally integrated and another part is not. To do that, we tried to develop a supplier panel so that we could have more visibility.

In this perimeter there are 4 families of purchases, below a table that summarizes all the types of purchases in this perimeter: 
Table 5: on the Body \& Electrical perimeter parts panel

\begin{tabular}{|l|l|}
\hline & - Glazing. \\
Body & - Watertight seal. \\
Equipment & - Wing mirror. \\
Purchasing & - Lighting. \\
& - Wiping. \\
\hline Purchases & - Air conditioner. \\
climate and & - Radiators. \\
cooling system & - Radiator hoses. \\
& - Compressors. \\
& - GMV: Ventilation \\
& motor unit. \\
\hline & - Clusters. \\
& - Door mechanism. \\
& - Hinge. \\
Purchasing & - Switch. \\
Multi-Media & - Combi switch. \\
and & - Door switches. \\
Mechatronics & - Electronic keypad. \\
& - Probes. \\
& - Speakers. \\
& - Antenna. \\
& -Microphone and displays. \\
& - Radio / Navigation \\
& system. \\
\hline Buying Harness, & - Wiring. \\
Energy Systems & - Drums. \\
& - Starter. \\
\hline & \\
\hline
\end{tabular}

Indeed, five buyers share among them these parts, their management, their supplier panel, and supply monitoring.

Indeed, this perimeter is very strategic, since it gathers a very interesting percentage of all parts worked on vehicles. That said, buyers must have background and training in the technical field and specifically, in mechanical and electronic engineering to handle negotiations very well with its supplier.

We have chosen the group of merchandise climate and cooling system, for a possible local integration, however before beginning the consultations, we have made a small diagnosis of this grouping of merchandise to study the parts not yet integrated locally and those potentially to be there in 2016 .

\section{Diagnosis and analysis of the parts group Climate and Cooling System}

We have created a table that includes all the families of purchases and the parts allocated to them. Subsequently the document was sent to the buyer who is responsible for the perimeter climate and cooling, so that he can tell us which purchasing families he is responsible for, their suppliers solicited and the parts that are integrated locally and have not yet been.

This support will help us to have a visibility on the parts that can be integrated locally and to identify it in order to launch the supplier consultations on these parts. 
Table 6: analysis of the climate and cooling system

\begin{tabular}{|c|c|c|c|c|c|c|}
\hline \multicolumn{2}{|c|}{$\begin{array}{l}\text { The parts of the climate } \\
\text { perimeter and cooling system }\end{array}$} & \multirow{3}{*}{ Buyers } & $\begin{array}{l}\text { Local } \\
\text { integra }\end{array}$ & \multirow{2}{*}{ Suppliers } & \multirow{2}{*}{ City } & \multirow{2}{*}{$\begin{array}{c}\text { Integra ted } \\
\text { Potentia } 12017 \\
\text { Yes } \\
\end{array}$} \\
\hline \multirow{8}{*}{$\begin{array}{l}\text { Climate } \\
\text { And cooling } \\
\text { system }\end{array}$} & Compressors & & No & & & \\
\hline & HVAC manual & & Yes & & & \\
\hline & $\begin{array}{l}\text { HVAC } \\
\text { regulated }\end{array}$ & & Yes & & & \\
\hline & GMV & & Yes & & & \\
\hline & Air guide & & Yes & & & \\
\hline & Radiator & & Yes & & & \\
\hline & Radiator hoses & & No & & & Yes \\
\hline & $\begin{array}{l}\text { Hoses for water } \\
\text { evacuation }\end{array}$ & & Yes & & & \\
\hline
\end{tabular}

This table is a summary on the integrated parts and the others that are potentially integrable for the year 2017 and for which we already have an idea on the feasibility of the project. This table contains the following:

Suppliers solicited for each commodity group.

$>$ The parts that will be integrated for the year 2016.

$>$ Potentially integrable parts for the year 2017.

After drawing up this table, the engineering department and the project purchases made a meeting to choose between the compressors and the radiator pipes for a possible local integration. We found that there is no international supplier installed in Morocco that would have the necessary technology to produce compressors of good quality. In the end Renault chose to start on the local sourcing of radiator pipes.

\subsubsection{The project framework}

We concluded that SMA will be interested in the supply of radiator pipes as shown in the table above shows that Renault has already integrated locally at SMA Casablanca. The water drain pipes that are more or less similar in their production than the radiator pipes, in addition SMA already has an experience effect in the production of radiator pipes since they produce this type of parts in its plants everywhere In the world for Renault and for other car manufacturers.

The choice of radiator pipes was validated by the engineering department, as well as the purchase projects including with the approval of Chamberlain Nicolas project manager local integration Renault Morocco. 
Raissouni Rajaa, Hamiche Mhamed, The Rate of Local Integration in the Supply Chain of A Car Manufacturer. Transactions on Machine Learning and Artificial Intelligence, Vol 5 No 4 August (2017); p: 803-825

The supplier SMA with its new site in Casablanca represents an opportunity to be seized by Renault. The table below summarizes the different levers of this project:

Table 7: Project Framework Summary

\begin{tabular}{|c|l|}
\hline Target Supplier & SMA Morocco \\
\hline Actual Supplier & INAS India \\
\hline Year of projection & $2017 / 2018 / 2019$ \\
\hline Turnover & 400000 Euro \\
\hline Projects & $\begin{array}{l}\text { Lodgy, Sandero, Dacia Logan, } \\
\text { Docker }\end{array}$ \\
\hline Impacted perimeter & $\begin{array}{l}\text { Radiator Inlet Hose } \\
\text { Radiator Outlet Hose } \\
\text { Heat Inlet Hose } \\
\text { Hose outlet radiator heating } \\
\text { Hose intake tank degassing } \\
\text { Hose outlet tank degassing } \\
\text { Hose purge }\end{array}$ \\
\hline
\end{tabular}

A precision, to clarify the confusion between the nature of the part and the references. Each part has a number of references, in the case of this project there are 800 references for the family of radiator pipe parts. The reference is a code which designates the technical characteristics of the part.

\subsection{Consultation phase}

Generally this phase is subdivided into two main components:

\subsubsection{The development of the purchase specifications}

In the Renault standard the purchase specification is constituted in the form of an RFI, Request for information. Indeed for the realization of the mission it is necessary to collect different information from different departments so that the file is in good and due form.

\section{The volume of vehicle projects}

At Renault each vehicle is associated with a specific code and a project manager responsible for the monitoring of the sourcing carried out. To do this consult the project managers purchase to have the volumes impacted by our sourcing on each type of vehicle namely: Docker, Dacia Logan, Sandero, lodgy.

Indeed, the designation of the volumes for the consultation is done according to a well-defined purchase strategy, to simplify, the project managers buy have two different volumes for each project, the first is the average volume and the second $c$ 'Is the maximum volume, this difference is due to the unpredictability of the scenarios throughout the duration of the project.

Generally, consultations are conducted on average volumes. This is what we did, for the simple reason that if the supplier is competitive on the average volume, it will automatically be competitive on the max volume. 


\section{Mix volumes and references}

The second information to be included in the RFI is the Mix volumes and references. The Mix volume is the criterion for which the supplier must return the volume of the previous table. In addition, since we do sourcing to radiator pipes, we must consider the types of motorization and the different mechanical aspects of the parts.

This information is retrieved from the engineering department. They provide us with the references of each type of radiator hoses and their mix with respect to the existing engines.

The references are like an engineering code that defines the degree of injection per second and the different mechanical dimensions. This information is strictly confidential. We were able to retrieve a table on the analysis of different types of motorization with their mixes in an anonymous way.

\section{Quality Renault}

The purchasing function is a transversal function. This is reflected in the RFI's drafting, which must specify the quality standards that Renault requires from its supplier.

To do this, the quality department recovers the quality objective of Renault for the years $(2016,2017$, 2018,2019 ) of the radiator pipes, as well as the degree of incident tolerated by quarter. This last criterion is measured by what is called the PPM indicator. This is means incident by thousands.

For example: a PPM = 5 goal, means that in a number of 1000 parts delivered to the Renault site, the degree of scrap and non-conforming parts must not exceed 5.

Indeed, Renault is developing another quality indicator for its suppliers. This is the ranking. It classifies its suppliers and awards a quality rating based on the experiences with the supplier, as well as its reputation and ISO quality certifications

After the recovery of the quality objectives, it is necessary to do the same for the logistics side. Except that the objectives of the logistics are the same as the previous year with the precision of the incoterm FCA. This precision gives transport responsibility to Renault.

\subsubsection{The technical file}

The purchasing file consists of two main elements: the RFI and the technical file. The responsibility for the elaboration of this last one weighs on the shoulders of the engineers.

In fact, this file contains the technical definition of the parts, specifying the 2D and 3D models, and the technology used for quality production and consistent with Renault standards.

\subsection{Analysis Phase}

The following two indicators need to be analyzed:

$>$ Transport encryptions.

$>$ Current CA analysis. 


\subsubsection{Transport encryption}

In order to calculate the transport gains that Renault can generate from this project, it is necessary to carry out a transport calculation, comparing the current logistic flow and the future flow of the radiator pipes. Below is a diagram of the two flows:

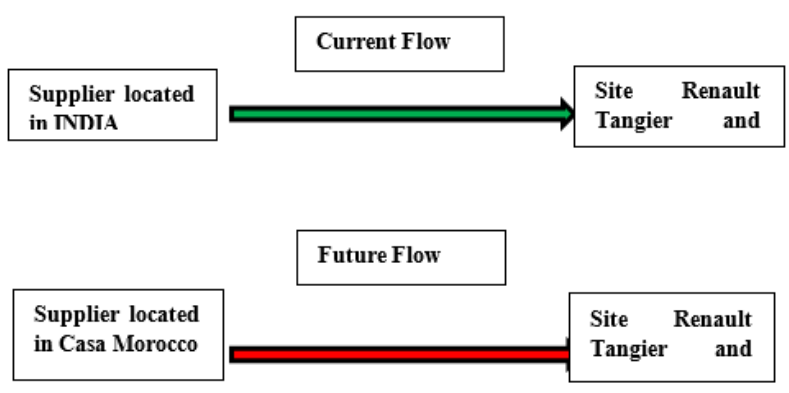

Figure 8: Logistic flows of radiator pipes

To compare the logistic costs of each stream there is a unit at Renault specializing in this transport encryption. It calculates the transport costs of the two flows.

The nature of the information collected for each reference is:

$>$ The types of projects, in other words the different vehicles impacted.

$>$ The weight of each reference: each reference has a specific weight. This information is provided by the engineering department of the company.

Daily rates: the volume that Renault wants to receive every day to avoid breaking the production chain.

$>$ The code of the packaging unit (CPU): the type of CPU used in order to know the number of parts that this packaging unit can contain.

$>$ The code of the handling unit (UM): the type of UM used in order to know the number of the CUs that the UM can contain.

$>$ The supplier site account and the customer account.

After collecting this information from different departments, the launch of transport encryption for current flows will be possible.

After a kick off, the engineering department deducts the nature of the CUs and the UMs that the supplier must use since the transport is provided by Renault, consequently, Renault launched the transport costing for this future flow.

The return of the two transport figures, made it possible to identify the transport gain that Renault can earn.

What we have deducted is that the transport gain will be 5.51 euro for each family of parts delivered to the Renault plant. 
For this purpose the Purchasing Department has established a current CA analysis and the prices that Renault pays for the radiator hoses in order to compare with the supplier's offer.

\subsubsection{Current turnover analysis}

The reference prices appear on a platform called SCOPP, which manages supplier contracts, their appointment, and the prices of all sourced references as well as supplier flows.

The list of references will be sent to a cell specializing in the administration of this platform, in order to retrieve the prices of each reference.

The objective was to realize the impact of total turnover of references consulted and to know the amount that Renault currently pays. Here is the result of the analysis in the form of a table:

Table 9: Turnover analysis

\begin{tabular}{|c|c|}
\hline The parts/year & price \\
\hline Radiator Inlet Hose & $23000,00 €$ \\
\hline Radiator Outlet Hose & $11000,00 €$ \\
\hline Heat Inlet Hose & $35000,00 €$ \\
\hline $\begin{array}{c}\text { Hose outlet radiator } \\
\text { heating }\end{array}$ & $38000,00 €$ \\
\hline $\begin{array}{c}\text { Hose intake tank } \\
\text { degassing }\end{array}$ & $100000,00 €$ \\
\hline $\begin{array}{c}\text { Hose outlet tank } \\
\text { degassing }\end{array}$ & $57000,00 €$ \\
\hline Hose purge & $19000,00 €$ \\
\hline Total & $\mathbf{2 8 3 0 0 0 , 0 0 €}$ \\
\hline
\end{tabular}

The turnover shown in this table is the amount that Renault is paying today. Vis-à-vis its supplier, it is necessary to specify that this table summarizes the turnover for each type of radiator pipes.

Indeed, each type of radiator pipes corresponds to a sum of references. At the end we have specified in the project framework that there are 800 references for all radiator pipe parts.

\subsection{Supplier return}

The supplier return was set at the second week of April, unfortunately, Renault did not receive the supplier offer on time.

As a result, Renault relaunched its demand, and this time Renault received an unfavorable return which expresses that the quantity of references sent is very large and it will take a long time to encrypt them on the form of an industrial process. In addition it has even specified that to produce the quantity requested it will need very large investments which are very expensive and that the requested technology does not exist in Morocco. Therefore Renault must expatriate it from their site located in Ukraine.

In short, Renault has deduced that the supplier is not competitive on all references. 


\subsection{Presentation and interpretation of results}

\subsubsection{Presentation of the results}

The SMA provider sent its quotation for the $20 \%$ references consulted. The supply generally consists of two parts. A part price of the piece and a logistics part. For the latter we have already carried out the transport costing and we have been able to show the transport gains. Here is the price suggested by SMA for the 12 references consulted ( $20 \%$ of total references):

Table 10: Offers SMA Casablanca

\begin{tabular}{|c|c|}
\hline The references & Unit price of SMA in $€$ \\
\hline Reference 1 & $21,23 €$ \\
\hline Reference 2 & $18,54 €$ \\
\hline Reference 3 & $28,29 €$ \\
\hline Reference 4 & $10,93 €$ \\
\hline Reference 5 & $12,48 €$ \\
\hline Reference 6 & $17,53 €$ \\
\hline Reference 7 & $15,05 €$ \\
\hline Reference 8 & $16,78 €$ \\
\hline Reference 9 & $20,60 €$ \\
\hline Reference 10 & $28,29 €$ \\
\hline Reference 11 & $16,79 €$ \\
\hline Reference 12 & $22,39 €$ \\
\hline Total & $\mathbf{2 2 8 , 9} €$ \\
\hline
\end{tabular}

The next step is to compare these prices with the current price. However, it must be taken into consideration that the encryption we have done previously was on all the parts, and consequently on all the references. For that we have redrafted our encryption to have our gain of transport only on the 12 referens concerned.

To summarize, we must compare the total supply. In other words the logistics part and the parts prices. Below the tables that presents the SMA offer and the offer of our current supplier with a precise and profound comparison:

Table 11 : Offers SMA Casablanca

\begin{tabular}{|c|c|c|c|}
\cline { 2 - 4 } \multicolumn{1}{c|}{} & \multicolumn{3}{c|}{ Offers SMA Casablanca } \\
\hline The references & $\begin{array}{c}\text { Unit price } \\
\text { per piece }\end{array}$ & $\begin{array}{c}\text { Current } \\
\text { transport } \\
\text { flows }\end{array}$ & Total price \\
\hline Reference 1 & $21,10 €$ & $0,13 €$ & $21,23 €$ \\
\hline Reference 2 & $18,35 €$ & $0,19 €$ & $18,54 €$ \\
\hline Reference 3 & $27,89 €$ & $0,40 €$ & $28,29 €$ \\
\hline Reference 4 & $10,66 €$ & $0,27 €$ & $10,93 €$ \\
\hline Reference 5 & $12,10 €$ & $0,38 €$ & $12,48 €$ \\
\hline Reference 6 & $17,20 €$ & $0,33 €$ & $17,53 €$ \\
\hline Reference 7 & $14,23 €$ & $0,80 €$ & $15,05 €$ \\
\hline Reference 8 & $16,20 €$ & $0,58 €$ & $16,78 €$ \\
\hline Reference 9 & $20,10 €$ & $0,50 €$ & $20,60 €$ \\
\hline Reference 10 & $28,12 €$ & $0,17 €$ & $28,29 €$ \\
\hline Reference 11 & $16,54 €$ & $0,25 €$ & $16,79 €$ \\
\hline Reference 12 & $22,13 €$ & $0,26 €$ & $22,39 €$ \\
\hline Total & $\mathbf{2 2 4 , 6 2 €}$ & $\mathbf{5 , 2 6} €$ & $\mathbf{2 2 8 , 9} €$ \\
\hline
\end{tabular}

Table 12: The current offer of INAS India

\begin{tabular}{|c|c|c|c|}
\cline { 2 - 4 } \multicolumn{1}{c|}{} & \multicolumn{3}{c|}{ Current Supplier Offer INAS India } \\
\hline The references & $\begin{array}{c}\text { Current unit } \\
\text { price of piece }\end{array}$ & $\begin{array}{c}\text { Current } \\
\text { transport flows }\end{array}$ & Total price \\
\hline Reference 1 & $16,95 €$ & $1,66 €$ & $18,61 €$ \\
\hline Reference 2 & $15,33 €$ & $0,85 €$ & $16,18 €$ \\
\hline Reference 3 & $28,56 €$ & $0,87 €$ & $29,43 €$ \\
\hline Reference 4 & $8,73 €$ & $0,93 €$ & $9,66 €$ \\
\hline Reference 5 & $8,66 €$ & $0,79 €$ & $9,45 €$ \\
\hline Reference 6 & $15,11 €$ & $0,58 €$ & $15,69 €$ \\
\hline Reference 7 & $12,56 €$ & $1,89 €$ & $14,45 €$ \\
\hline Reference 8 & $11,44 €$ & $1,05 €$ & $12,49 €$ \\
\hline Reference 9 & $17,98 €$ & $1,13 €$ & $19,11 €$ \\
\hline Reference 10 & $20,81 €$ & $0,47 €$ & $21,28 €$ \\
\hline Reference 11 & $15,35 €$ & $0,66 €$ & $16,01 €$ \\
\hline Reference 12 & $16,31 €$ & $0,75 €$ & $17,06 €$ \\
\hline Total & $\mathbf{1 8 7 , 7 9} €$ & $\mathbf{1 1 , 6 3} €$ & $\mathbf{1 9 9}, \mathbf{4 2} €$ \\
\hline \multicolumn{4}{|c}{}
\end{tabular}


And finally the table of the comparison of the two offers:

Table 13: Comparison of offers

\begin{tabular}{|c|c|c|}
\hline \multicolumn{3}{|c|}{ Comparison of offers } \\
\hline \hline Price per piece & Transport flow & Total Delta $+/$ - \\
\hline $4,15 €$ & $-1,53 €$ & $2,62 €$ \\
\hline $3,02 €$ & $-0,66 €$ & $2,36 €$ \\
\hline$-0,67 €$ & $-0,47 €$ & $1,14 €$ \\
\hline $1,93 €$ & $-0,66 €$ & $1,27 €$ \\
\hline $3,44 €$ & $-0,41 €$ & $3,03 €$ \\
\hline $2,09 €$ & $-0,25 €$ & $1,84 €$ \\
\hline $1,67 €$ & $-1,09 €$ & $0,58 €$ \\
\hline $4,76 €$ & $-0,47 €$ & $4,29 €$ \\
\hline $2.12 €$ & $-0,63 €$ & $1,49 €$ \\
\hline $7,31 €$ & $-0,30 €$ & $7,01 €$ \\
\hline $1,19 €$ & $-0,41 €$ & $0,78 €$ \\
\hline $5,82 €$ & $-0,49 €$ & $5,33 €$ \\
\hline $36,83 €$ & $-7,37 €$ & $31,74 €$ \\
\hline
\end{tabular}

The return of the SMA for the 12 references will allow us to check our local sourcing problem, and the results interpretation will be presented in the next chapter.

\subsubsection{Results and interpretation}

The competitiveness of suppliers is a fundamental criterion for supplier selection at Renault. Before the launch of the project we have established criteria that we want to find at the supplier consulted, namely competitive and profitability as well as performance.

The total price offered by SMA exceeds mostly the current price of INAS India even though we have gained in terms of transportation. But on the actual price of the piece the offer of INAS India is more competitive than that of SMA.

After an analysis to understand this price gap, we found that this difference is due to the large investments that SMA has set up to produce these references. A very advanced technology to produce only 12 references this increased the fixed costs and by default the cost price of SMA.

The lack of propulsion technology in Morocco was the main obstacle for this project. In addition there are other projects that are frozen for the same cause. When the supplier makes his calculations of the costs of installing the technology locally he finds that the project is not profitable and that his initial investment far exceeds the generated cash flows.

Indeed, most suppliers do not want to commit to low quantities especially for parts that require advanced technologies in their manufacturing process. The arrival of PSA in 2019 will make this demand more or less high and therefore will be an opportunity for Renault to unblock these frozen projects.

The levers and the stakes of local integration depend directly on the competitiveness of existing suppliers locally, so multinationals must seek to cut this dependence on suppliers in order to improve their performance through local sourcing. 
Raissouni Rajaa, Hamiche Mhamed, The Rate of Local Integration in the Supply Chain of A Car Manufacturer. Transactions on Machine Learning and Artificial Intelligence, Vol 5 No 4 August (2017); p: 803-825

It is obvious that the local integration makes it possible to gain in terms of logistics, but not in the case of parts prices. The installation of investments and the non-existing technology impacts the total price of the parts.

We decided to continue looking for another supplier to produce these parts, while Renault will continue to source from INAS India.

Our study led us to conclude that local sourcing does not always contribute to purchasing optimization and that sourcing to the International may be more competitive than local sourcing even if the company gains tremendously in terms of logistics.

Indeed, we have noticed that sourcing actually reduces logistics costs, but multinationals are looking to reduce their total purchase costs in terms of transport and in terms of products themselves.

\section{General conclusion}

Local sourcing is a very complicated process in non-industrialized countries. Thanks to a solid industrial fabric, an experience effect, and advanced technologies available within the country Renault was able to achieve a local integration rate of $90 \%$ in India.

The lack of technology and the effect of experience make it very difficult to establish local integration because investment costs are enormous. By default, the competitiveness of local suppliers in relation to international suppliers' prices will be impacted. Of course, ecosystem conventions have been established to solve this problem of non-competitiveness of local suppliers. This was possible through the subsidies that the Moroccan State undertakes to grant suppliers to encourage them to make the necessary investments.

Indeed, the problem of the departure was to know if the local sourcing always allows optimizing the purchase costs of the multinationals. To verify this hypothesis we have piloted a project of local integration for the multinational Renault.

We have found that local integration does not always optimize the purchasing costs of multinationals because of the lack of competitiveness of local suppliers, especially in developing countries.

\section{BIBLIOGRAPHY AND WEBOGRAPHY}

[1] Op.cit., Bozarth, Handfield, Introduction to Operations and Supply Chain management, Pearson, 2007

[2] Supply Chain Brain, U.S. and China Are the Riskiest Geographies for Sourcing and Manufacturing.

[3] AberdeenGroup, Low-Cost Country Sourcing : Success Strategies Maximizing and Sustaining the Next Big Supply Savings Opportunity, Juin 2005

[4] Sara Ireton, Global Sourcing Checklist. Industry Week, janvier 2007, p. 40

[5] Mike Jones, Domestic costs of foreign sourcing. Material Handling Management, février 2008, p. 40-41

[6] Sean Delaney, Delivering Value in both good and bad times, E-sourcing Forum, 14 juillet 2008 
Transactions on Machine Learning and Artificial Intelligence Vol 5 No 4, Aug 2017

[7] .N. Sheth, « présentation d'un modèle de comportement des acheteurs industriels

[8] Le Supplier Choice Model » WOODSID \& VYAS (1984;1986; 1987)

[9] Roger Pérotin marketing achats, stratégies et tactiques, Edition 2010

[10] SidhuSephardi, Sourcing strategy, principles, policy and designs, 2005, Springer

[11] Salons Solutions, discussion informelle avec des décideurs, CNIT Paris La Défense, 30 septembre 2008.

[12] Collectif, Encyclopédie de gestion, article "Stratégie d’entreprise et économie industrielle ", écrit par A. Desreumaux, Economica, 1997. 